\begin{tabular}{c} 
International Journal of Engineering \& Technology, $7(2.12)(2018) 292-295$ \\
International Journal of Engineering \& Technology \\
Website: www.sciencepubco.com/index.php/IJET \\
Research Paper \\
\hline
\end{tabular}

\title{
Optimal design for improving torque performance of permanent magnet motor
}

\author{
Tae-Kyoung Bang ${ }^{1 *}$, Kyung-Hun Shin ${ }^{1}$, Jeong-In Lee ${ }^{1}$, Cheol Han ${ }^{1}$, \\ Sung-Kook Cho ${ }^{1}$, Han-Wook Cho ${ }^{2}$, Jang-Young Choi ${ }^{2}$ \\ ${ }^{1}$ Dept. of Electrical Engineering, Chung-nam National University, 99, Dae-hak-ro, Yusung-gu, Daejeon, 34134, Republic of Korea \\ ${ }^{2}$ Dept. of Electric, Electronic \& Communication Eng. Edu., Chung-nam National University, 99, Dae-hak-ro, \\ Yusung-gu, Daejeon, 34134, Republic of Korea \\ *Corresponding author E-mail: bangtk77@cnu.ac.kr
}

\begin{abstract}
Background/Objectives: This paper deals with the optimal design of the BLDC motor considering a rotor structure that is used to electrically drive tools. Generally, electrically driven tools employ the BLDC motor, which should be able to operate in high-speed and highvibration environments. However, it has the disadvantages of a high torque ripple and significant waveform fluctuation. Therefore, it is necessary to optimize it according to the usage condition.

Methods/Statistical analysis: In improving the torque performance, this study performed the optimization process by employing the Taguchi method, which can achieve a robust design based on the design variables. In the optimization process, the objective functions are set using a weighting ratio depending on the importance of the objective function as back EMF, torque performance, and loss. Through the optimization process, the optimal design point that improved the performance of the objective function is derived. The improved design that applied the optimal design point is compared with the original design by using the finite element method (FEM) analysis results.

Findings: In this study, the optimum design of the motor according to the design variables and the objective function is derived through the optimum design method using the Taguchi method by adopting the motor for the electrically driven tool as the interior permanent magnet type BLDC motor and the FEM results. Moreover, by comparing the analysis results with the optimized model and the initial model, the optimum design point that satisfies the restriction specification and the rated specification was found.

Improvements/Applications: The optimum design point was found by using the Taguchi method and the loss and torque characteristics were improved.
\end{abstract}

Keywords: Electrically Driven Tools; Taguchi Method; Optimization; Torque Performance; BLDC Motor.

\section{Introduction}

In the field of electrically driven tools, it is required to increase the equipment speed used for cutting and machining. Furthermore, as the use of portable electrically driven tools is expanded, the size of the motor has to be reduced by using a permanent magnet. The interior permanent magnet (IPM) motor has a robust rotor structure that is inserted in the permanent magnet, which is advantageous for high-speed operation and manufacture. In this study, the motor employed in the electrically driven tools is the IPM type BLDC motor, which does not require the commutator and mechanical brush, thus making it more structurally durable and compact to satisfy the needs of operating in different environments and portability. Using the Taguchi design method, the optimization is performed according to the objective function of the design variables that employed the weighting ratio depending on the importance of the objective function, and the optimal design is validated by comparing the original model with the analysis result. The optimal design of the IPM motor using the Taguchi method has been studied as an object function such as cogging torque, torque ripple, power, and losses that used the weighting ratio depending on the importance of the objective function. Through the optimization process, the optimal design point that improved the performance of the objective function is derived. However, most of these studies were conducted in PMSM and did not include the BLDC motor field for the electrically driven tools model[1,2].

\section{Optimization using taguchi method}

\subsection{The initial design}

This paper deals with the optimal design of the IPM type BLDC motor for torque performance by using the Taguchi design method. Table 1 shows the basic design specifications of the highspeed BLDC motor for power tools. Permanent magnet data was applied based on the outside temperature of about $120{ }^{\circ} \mathrm{C}$ so that the characteristics would not be reduced even during long operations. From the design specification, the size of the initial design model could be derived from the TRV method. The TRV method describes the availability of torque generation according to total rotor volume $\mathrm{e}^{3,4}$. Therefore, it is common to compare the initial and optimal design size with the TRV method for a given design specification. The initial design structure is shown in Fig. 1. For mechanical design purposes, the rotor bridge thickness and stator Yoke thickness were fixed. 


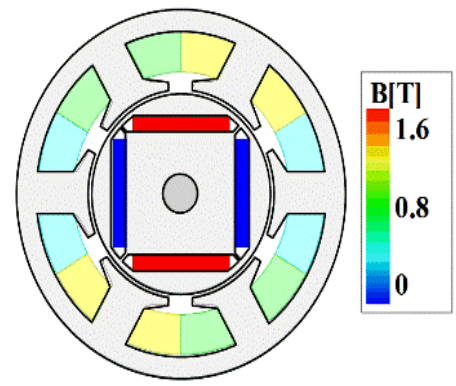

(a)

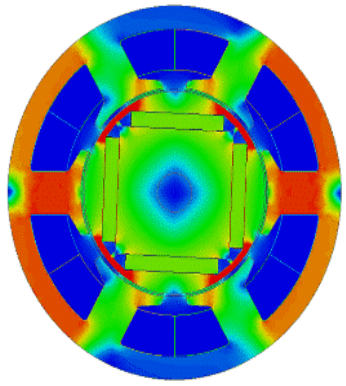

(b)
Fig. 1: Shape of Initial Sizing Results.

(a) Initial Design Shape (b) Magnetic Flux Density Distribution of Initial Design

\begin{tabular}{ll} 
& Table 1: The Design Specification \\
\hline Parameter & Value \\
\hline Pole / Slot & $4 / 6$ \\
Maximum Power & $400 \mathrm{~W}$ \\
Rated Speed & $17000 \mathrm{rpm} \uparrow$ \\
Rated Torque & $140 \mathrm{mNm}$ \\
Stack Length & $18 \mathrm{~mm} \downarrow$ \\
External Diameter & $50 \mathrm{~mm} \downarrow$ \\
\hline
\end{tabular}

\subsubsection{Voltage limit}

The maximum voltage that can be applied to the BLDC motor is determined by the DC link voltage Vdc, and the usable voltage varies depending on the current control method even within the voltage range ${ }^{5}$. Because the BLDC motor is generally driven by the square wave control and adopts delta wiring, the maximum applied voltage of the motor can be expressed as Equation (1), where $\eta$ is a constant that takes into account the leakage inductance, the voltage drop due to resistance, and voltage drops due to inverter switching elements from 0.85 to 0.95 .

V_max $=\eta \times V \_d c$

The initial design specification value is derived from the voltage limit and the TRV. Based on the initial design, the optimization process objective function is set by the characteristic analysis results.

\subsubsection{Torque \& losses}

BLDC motors use the a, b, c phase equations directly instead of using the $d-q$ axis coordinate transformation as in synchronous motors. Thus, the torque can be derived from the voltage equation and expressed as Equation (2). Therefore, the torque ripple is generated according to the harmonic component contained in the back electromotive force and current.

$\mathrm{T}=\mathrm{P} / \mathrm{w}_{-} \mathrm{m}=\left(\mathrm{e}_{-} \mathrm{a} \mathrm{i}_{-} \mathrm{a}+\mathrm{e}_{-} \mathrm{b} \mathrm{i}_{-} \mathrm{b}+\mathrm{e}_{-} \mathrm{c} \mathrm{i}_{-} \mathrm{c}\right) / \mathrm{w}_{-} \mathrm{m}$

$\mathrm{T}:$ torque, $\mathrm{w}_{\mathrm{m}}$ : angular speed, $\mathrm{e}_{\mathrm{a}}, \mathrm{e}_{\mathrm{b}}, \mathrm{e}_{\mathrm{c}}$ : phase back-EMF components, $i_{a}, i_{b}, i_{c}$ : phase current components

The eddy current of the permanent magnet is generated in the permanent magnet through the armature reaction by the current flowing in the armature winding, which generates heat loss. The permanent magnet eddy current loss is expressed by Equation (3).

$\mathrm{P}_{-} \mathrm{e}^{\wedge^{\prime}}=\int|J|^{\wedge} 2 / 6 \mathrm{dv}$

$\mathrm{J}, \sigma$, and $v$ are the eddy current density, the conductivity, and the volume of the permanent magnet flowing in the permanent magnet, respectively. The iron loss is derived from the Steinmetz equation modified by Berroti and is given by Equation (4) [six, seven].

$P_{-} c=P \_h+P \_e+P \_a=k_{-} h f^{\wedge} n+k_{-} e f^{\wedge} 2 B^{\wedge} 2+$

$\mathrm{k} \_\mathrm{a}^{\wedge} 1 . \overline{5} \mathrm{~B}^{\wedge} 1 . \overline{5}$
$\mathrm{P}_{\mathrm{c}}$ : core loss, $\mathrm{P}_{\mathrm{h}}:$ hysteresis loss, $\mathrm{P}_{\mathrm{e}}:$ eddy current loss, $\mathrm{k}_{\mathrm{h}}:$ hysteresis coefficient, $\mathrm{k}_{\mathrm{e}}$ : eddy current coefficient, $\mathrm{k}_{\mathrm{a}}$ : ideal eddy current coefficient.

\subsection{Optimization of rotor structure by using taguchi method}

To improve the torque performance and loss reduction of the motor, the Taguchi method is adopted for the optimum design. This method is designed as a quality improvement technique that can achieve a robust design. The optimization process of the Taguchi method is shown in Fig. 2. Through the optimization process, the objective function must be set to improve for a purpose. Thus, the application of the optimal model is for electrically driven tools such as a drill so that it can have constant power; if it has fluctuating power, it cannot operate with a good performance. In this study, the objective functions are set as torque performance and losses for improving the torque fluctuation and efficiency. Next, a control factor and noise factor must be set. The control factor is the factor that affects the characteristic according to the change, which is controllable as the design variable. The noise factors are influential in the characteristics but are not controllable. The application of the design model is driven by the battery and it is set to the noise factor by the difference of the charge voltage. In the design model, the charging voltage varies from $18 \mathrm{~V}$ to $18.6 \mathrm{~V}$, depending on the battery cell of about $0.6 \mathrm{~V}$ due to manufacturing reasons. Table 2 shows the control factors and noise factors. The design variable of the optimization process for improving the torque performance is shown in Fig. 3.

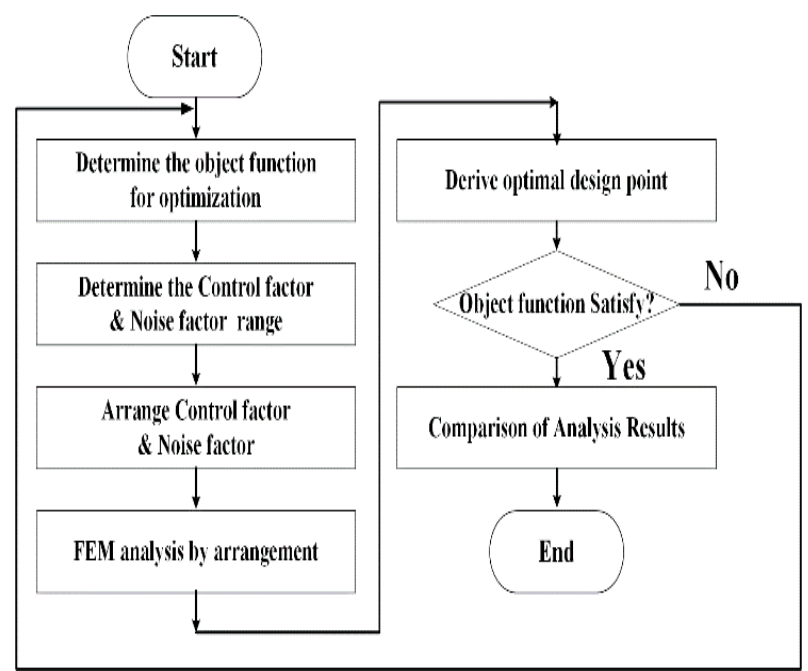

Fig. 2: Optimization Process Using Taguchi Method.

Table 2: Control Factor and the Noise Factor for Object Function Control Factor

\begin{tabular}{llll}
\hline A PM ratio & 0.70 & 0.75 & 0.80 \\
$\mathrm{~B} \quad$ PM Thickness & $1.0 \mathrm{~mm}$ & $1.5 \mathrm{~mm}$ & $2.0 \mathrm{~mm}$ \\
$\mathrm{C} \quad$ Rib Thickness & $0.5 \mathrm{~mm}$ & $1.0 \mathrm{~mm}$ & $1.5 \mathrm{~mm}$ \\
Noise Factor & & & \\
$\mathrm{N} \quad$ Voltage & $18 \mathrm{~V}$ & $18.3 \mathrm{~V}$ & $18.6 \mathrm{~V}$ \\
\hline
\end{tabular}

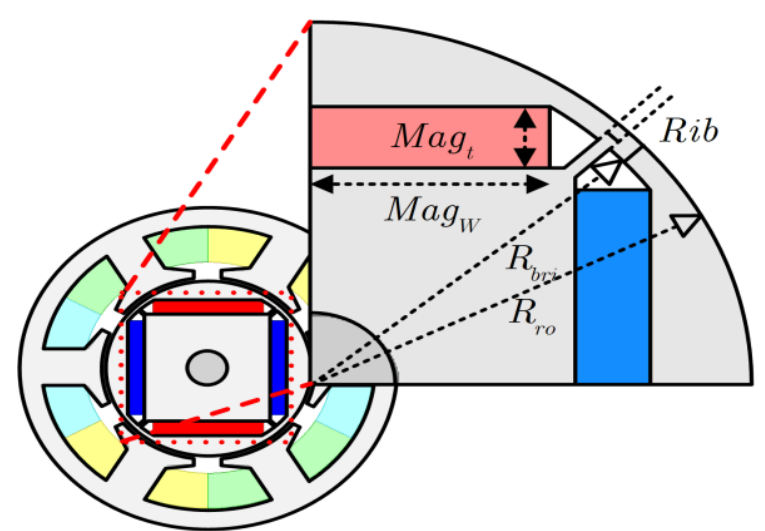

Fig. 3: Optimal Design Variable. 
To set the analysis order number, an orthogonal array is employed in the Taguchi method. In this study, to determine the analytical order number using the three-level three control factor, the inner array is arranged as the control factor and the outer array is arranged as the noise factor. In the Taguchi method, there are three types of characteristics: smaller the better, larger the better, and nominal best characteristics. The BLDC motor characteristics could be divided into two types: smaller the better and larger the better characteristics. For instance, the back EMF constant, torque, and efficiency are considered better when they are larger, so these characteristics could be called larger the better characteristics, whereas the torque ripple, cogging torque, THD, and losses are considered better when they are smaller, so these characteristics could be called smaller the better characteristics. Therefore, in the case of many optimization objective functions as in this paper, it is difficult to derive the optimum value Many researchers have all studied this approach ${ }^{8-11}$. The process of deriving the optimal point value is as shown Table 3 .

Table 3: Control Factor and Noise Factor Arrangement Using Orthogonal Array

\begin{tabular}{lllllll}
\hline Analysis Order Number & \multicolumn{3}{l}{ Inner Array } & \multicolumn{2}{l}{ Outer array } \\
& A & B & C & N1 & N2 & N3 \\
\hline 1 & 1 & 1 & 1 & R11 & R12 & R13 \\
2 & 1 & 2 & 2 & R21 & R22 & R23 \\
3 & 1 & 3 & 3 & R31 & R32 & R33 \\
4 & 2 & 1 & 2 & R41 & R42 & R43 \\
5 & 2 & 2 & 3 & R51 & R52 & R53 \\
6 & 2 & 3 & 1 & R61 & R62 & R63 \\
7 & 3 & 1 & 3 & R71 & R72 & R73 \\
8 & 3 & 2 & 1 & R81 & R82 & R83 \\
9 & 3 & 3 & 2 & R91 & R92 & R93 \\
\hline
\end{tabular}

In the Taguchi method, the degree of improvement used in the optimization is expressed as a performance measure, and it is obtained as a signal to noise ratio ( $\mathrm{S} / \mathrm{N}$ ratio). The $\mathrm{S} / \mathrm{N}$ ratio calculation varies according to the types of characteristics. It is arranged in the orthogonal array according to the analysis order number, thus it calculates the mean and standard deviation. The derived value is used to obtain the performance measure. The $\mathrm{S} / \mathrm{N}$ ratio needs to be normalized to optimize the design using the $\mathrm{S} / \mathrm{N}$ ratio values and the weight of the target coefficients. The normalized $\mathrm{S} / \mathrm{N}$ ratio is calculated using the mean and standard deviation of the $\mathrm{S} / \mathrm{N}$ as in Equation (5). The subscript $\mathrm{p}$ stands for the order of the objective function. Finally, weighting is applied using Equation (6) to calculate the combined $\mathrm{S} / \mathrm{N}$ ratio. The weights are sorted according to the order of the importance of the objective function to optimize [11], [12].

$$
\begin{aligned}
& \left.\left(\mathrm{SN}_{-} \mathrm{p}^{\wedge} *\right)\right)_{-} \mathrm{k}=\left(\left(\mathrm{SN}_{-} \mathrm{p}\right) \_\mathrm{k}-\left(\left(\mathrm{SN}_{-} \mathrm{p}\right)^{-}\right)\right) /\left(\mathrm{s} . \mathrm{d}\left(\mathrm{SN} \_\mathrm{p}\right)\right) \\
& (\mathrm{TS})_{\mathrm{k}}=\sum_{\mathrm{i}=1}^{\mathrm{p}} \mathrm{w}_{\mathrm{i}}\left(\mathrm{SN}_{\mathrm{i}}^{*}\right)_{\mathrm{k}}
\end{aligned}
$$

$\mathrm{p}$ : objective function number, $\mathrm{k}$ : analysis order number, $\left(\overline{\mathrm{SN}_{\mathrm{p}}}\right)$ : $\mathrm{S} / \mathrm{N}$ ratio mean corresponding to the objective function $\mathrm{p}$, s. $d\left(\mathrm{SN}_{\mathrm{p}}\right): \mathrm{S} / \mathrm{N}$ ratio standard deviation corresponding to the objective function $\mathrm{p}, \mathrm{w}_{\mathrm{i}}$ : weighting corresponding to the objective function.
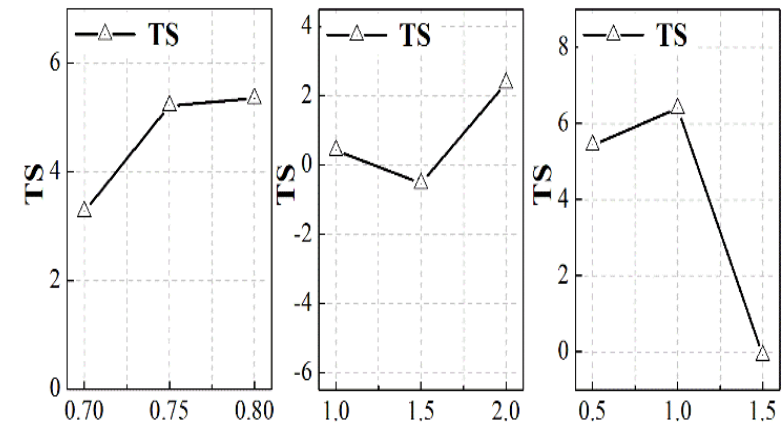

Pole Arc Ratio (\%) Magnet Thickness (mm) Rib Thickness (mm) Fig. 4: Optimal Design Results According to Multi-Objective Function.

Table 4: Weighting Ratio of Objective Function

\begin{tabular}{llllll}
$\begin{array}{l}\text { Object } \\
\text { Function }\end{array}$ & Back & $\begin{array}{l}\text { Torque } \\
\text { Ripple }\end{array}$ & $\begin{array}{l}\text { Cogging } \\
\text { Torque }\end{array}$ & $\begin{array}{l}\text { Core } \\
\text { Loss }\end{array}$ & $\begin{array}{l}\text { PM } \\
\text { Eddy } \\
\text { Loss }\end{array}$ \\
\hline Weighting & 0.2 & 0.3 & 0.3 & 0.1 & 0.1 \\
\hline
\end{tabular}

In Equation (6), the performance measure depends on the weight. Therefore, weights should be appropriately selected in the optimization process. The weights in this paper are shown in Table 4. The optimization points derived from the applied weights are shown in Fig. 4.

\section{Results and discussion}

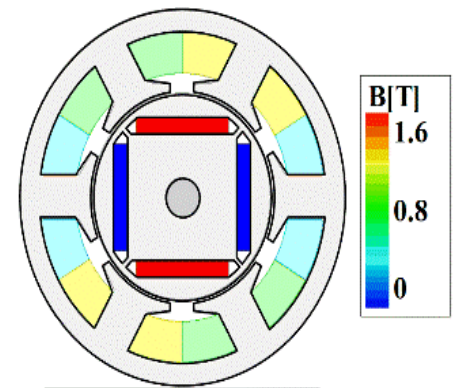

(a)

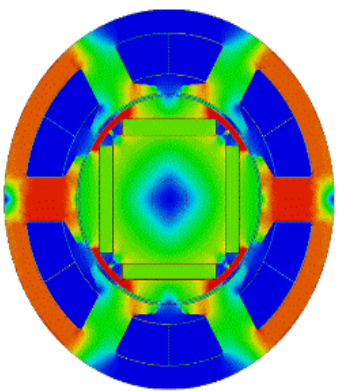

(b)
Fig. 5. Shape of Optimization Result.

(a) Optimal Design Shape (b) Magnetic Flux Density Distribution of Optimal Design.
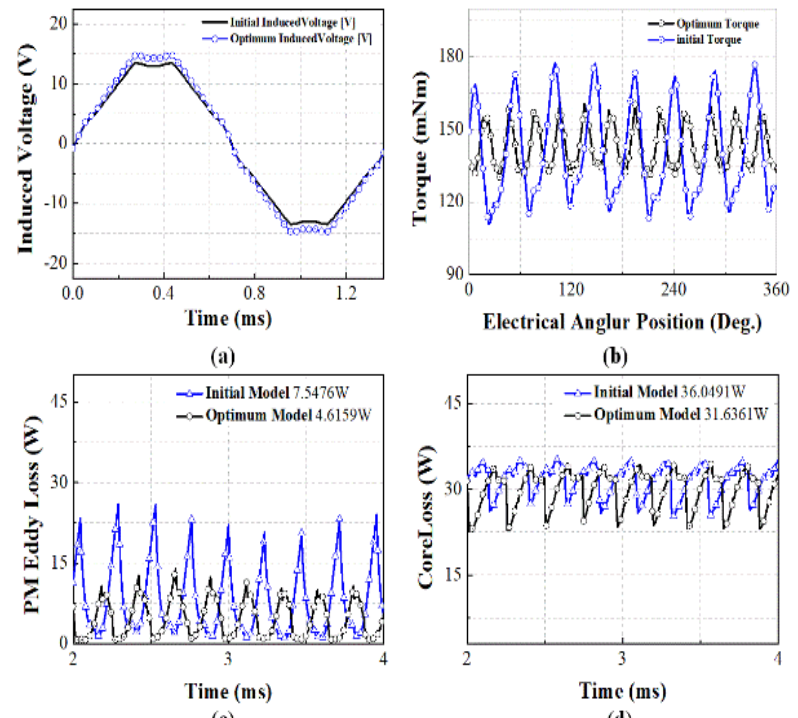

(d)

Fig. 6: Comparison of Optimal Model Characteristics Analysis Results. 
(a) Back-EMF (b) Torque Ripple (c) Permanent Magnet Eddy Current Loss (d) Core Loss

The comparison of the optimum design model and the initial model and the magnetic flux density distribution derived from the optimization process is shown in Fig. 5, which shows that the flux density saturation of the stator is reduced. It affects the torque performance and losses. The shape of the back EMF and the peak value are almost the same. The torque ripple is reduced by about $53.1 \%$ and the iron loss is reduced by about $4.9 \%$. The permanent magnet eddy current loss is reduced by about $40 \%$ and the copper loss is reduced by about $6.8 \%$. Therefore, it is shown that optimal design is possible using the Taguchi method. The comparison of the results is shown in Fig. 6. The optimal design point may not be the optimal point because the stator and rotor specification are fixed for the purpose of the mechanical design. However, the optimum design method is shown to be effective through comparison between the analysis results of the design models.

\section{Conclusion}

This paper deals with the optimal design of a high-speed permanent magnet motor with respect to machine applications by using the Taguchi method and finite element analysis. The torque and loss characteristics with optimal rotor structure are compared with the initial design to verify the validity of the design method. The comparison of the analysis results at the derived optimum design point indicates that the output torque average increased by $1.1 \%$ and the torque ripple was reduced by $53.3 \%$. Therefore, this optimal design method is considered to be effective.

\section{Acknowledgment}

This research was supported by a grant from National R\&D Project of "Development of Wave Energy Converters Applicable to Breakwater and Connected to Micro-Grid with Energy Storage System" funded by Ministry of Oceans and Fisheries, Korea (PMS3600).

This work was supported by the Basic Research Laboratory (BRL) of the National Research Foundation (NRF-2017R1A4A1015744) funded by the Korean government.

\section{References}

[1] K. C. Kim, J. Lee, H. J. Kim, and D. H. Koo, Multiobjective Optimal Design for Interior Permanent Magnet Synchronous Motor, IEEE Trans. Magn., 2009 March, 45(3), pp. 1780-1783.

[2] A. M. Omekanda, Robust Torque and Torque-per-Inertia Optimization of a Switched Reluctance Motor Using the Taguchi Methods, IEEE Trans. Ind. Appl., March/April 2006. 42(2), pp. 473-477.

[3] S. Brisset, F. Gillon, S. Vivier, and P. Brochet, Optimization with experimental design: an approach using Taguchi's methodology and finite element simulations, IEEE Trans. Magn., 2001 September, 37(5), pp. 3530-3533.

[4] K. C. Kim, D. H. Koo, J. P. Hong, and J. Lee A Study on the Characteristics Due to Pole-Arc to Pole-Pitch Ratio and Saliency to Improve Torque Performance of IPMSM, IEEE Trans. Magn., 2007 June, 43(6), pp. 2516-2518.

[5] D. Hanselman, Brushless Motors: Magnetic Design, Performance and Control of Brushless DC and Permanent Magnet Synchronous Motors, E-Man Press LLC, 2012.

[6] K. Yamazaki, and A. Abe, Loss Investigation of Interior Permanent-Magnet Motors Considering Carrier Harmonics and Magnet Eddy Current," IEEE Trans. Ind. Appl., 2009 March/April, 45(2), pp. 659-665.

[7] K. Yamazaki, and N. Fukushima, Iron-Loss Modeling for Rotating Machines Comparison Between Bertotti's Three-Term Expression and 3-D Eddy-Current Analysis, IEEE Trans. Magn., 2010, August, 46 (8), pp. 3121-3124

[8] H. T. Wang, Z. J. Liu, S. X. Chen, and J. P. Yang, Application of Taguchi Method to Robust Design of BLDC Motor Performance, IEEE Trans. Magn., 1999 September, 35(5), pp. 3700-3702,
[9] S. I. Kim, J. Y. Lee, Y. K. Kim, J. P. Hong, Y. Hur, and Y. H. Jung, Optimization for Reduction of Torque Ripple in Interior Permanent Magnet Motor by Using the Taguchi Method, IEEE Trans. Magn., 2005 May, 41(5), pp. 1796-1799.

[10] T.S. Low, S. Chen, and X. Gao, Robust Torque Optimization for BLDC Spindle Motors, IEEE Trans. Ind. Elect., June. 2001, 48(3) pp. 656-663.

[11] H. S. Kim, Y. M. You, and B. I. Kwon, Rotor Shape Optimization of Interior Permanent Magnet BLDC Motor According to Magnetization Direction, IEEE Trans. Magn., 2013 May, 49(5), pp. 2193 2196.

[12] K. C. Kim, J. S. Ahn, S. H. Won, J. P. Hong, and J. Lee, A Study on the Optimal Design of SynRM for the High Torque and Power Factor," IEEE Trans. Magn., 2007 June 43 (6), pp. 2543-2545. 